\title{
UNA EVALUACIÓN PARA LA ESCUELA DE HOY
}

\author{
Norma Constanza Castaño Cuéllar \\ Departamento de Biología.
}

\begin{abstract}
This paper intends to show that the concept of evaluation is related to the ideas that one has about pedagogy, education and culture.. It shows that the role that we play as teachers, our own conceptions of knowledge and the way we organize the curriculum are also elements of critical importance to these ideas.

Finally, the paper talks about the need for the evaluation process to be considered within specific cultural conditions, as part of the learning process and also as part of a global didactic strategy; so that it could guide us in the decision making process that would lead us to the transformation our educational practice.
\end{abstract}

\section{RESUMEN}

El texto pretende mostrar que el concepto de evaluación está relacionado con las ideas que se tienen acerca de pedagogía, educación y cultura. De la misma manera, muestra que en estas concepciones el rol que desempeñamos como docentes, también juega un importante papel; al igual que las concepciones que se tienen de conocimiento y de la forma como se estructura el currículum.

Finalmente se alude a la necesidad que los procesos de evaluación se consideren dentro de unas condiciones culturales, como proceso de conocimiento y parte del proceso didáctico de modo que nos oriente en la toma de decisiones para transformar las prácticas educativas.

\section{LA EVALUACIÓN COMO LEGITIMACIÓN DE LAS CULTURAS DOMINANTES}

La evaluación se ha asociado con palabras como apreciación, estimación, atribución de valor o juzgamiento. La evaluación juzga la enseñanza y juzga el aprendizaje; le atribuye valor a los actos y a las prácticas de los docentes y da cuenta del aprendizaje de los estudiantes.

Pensamos la evaluación en torno a conocimientos, actitudes, habilidades, competencias..., que se logran consolidar o lo que se resiste a hacerlo. Pensamos en la evaluación como medida de los aprendizajes en el mismo momento en que ocurren, pero ya empezamos a vislumbrar que los aprendizajes significativos necesitan consolidarse en el tiempo e incluso que el aprendizaje significativo se sucede fuera del ámbito escolar; o si

\footnotetext{
*Profesora universidad Pedagógica Nacional.
} 
no por qué un deportista calificado demuestra un alto rendimiento en las competencias y pierde logros en el área de educación física?

De otro lado empezamos a reconocer el papel que juegan las creencias de los docentes en la evaluación de los procesos ce aprendizaje. El estudio ya clásico de ROSENTHAL y JACOBSON (1980) muestra cómo las expectativas que los maestros tienen de los alumnos y de su rendimiento se convierten en una profecía que se cumple inexorablemente. Otro estudio de LITWIN (1998) muestra además que el halo que rodea algunas de las conductas de los estudiantes, como el orden, la buena letra, la participación en clase, ha llevado a que se consignen estas actitudes como expresión de buen aprendizaje y tienen influencia en las evaluaciones que realizan los docentes incrementando o disminuyendo las calificaciones.

Para no ir tan lejos, la investigación Estilos Cognitivos y Estilos de Aprendizaje en Colombia, (HEDERICH, 1998) muestra que la escuela privilegia un solo tipo de pensamiento, el pensamiento hipotético deductivo, analítico, y que en consecuencia los estudiantes que han logrado desarrollarlo son los que alcanzan las evaluaciones más altas. ¿Qué pasa con quienes han desarrollado otros formas de pensamiento? Seguramente la escuela los excluyó y les puso todas las trabas posibles hasta que se deshizo de ellos.

No podemos dejar de lado, que la escuela está en el centro de un dispositivo cultural y en la división social del trabajo, la palabra cultura es el emblema de la dignidad, del valor social (COMBESSIE, 1998). No podemos olvidar que el maestro mismo es producto de la cultura y se encuentra implicado en ella. Como si fuera poco impone una legitimidad cultural, es decir, así nos duela, es el ejecutante de las culturas dominantes y en consecuencia el portador de los valores positivos de aquellos grupos sociales que se pueden llamar "cultos', intelectuales", cercanos al poder económico y político. Esto significa también que hay otras culturas subordinadas, descalificadas incluso como prácticas culturales y no muy apresuradamente uno podría decir que a estas pertenecen las que no se consideran cultas", como por ejemplo las prácticas infantiles y adolescentes. Es entonces cuando relacionando cultura y evaluación, hablamos de "fracaso escolar" transformando en veredicto esas diferencias culturales y consagrando esas relaciones definidas y estructuradas por formas dominantes, de las cuales seguramente no somos conscientes; pero las vemos más elaboradas (tienen discursos) y consideramos que las otras" son inferiores e indignas, pues se basan en prácticas no discursivas. Acordémonos de prácticas deportivas, artísticas, artesanales, por el ejemplo.

\section{LOS RETOSQUETENEMOS COMO DOCENTES}

En esta perspectiva, nos corresponde admitir que los cambios que se han venido gestando en el sistema educativo, nos colocan como docentes, ante retos muy significativos, de los cuales quiero resaltar unos cuantos que a mi manera de ver se relacionan estrechamente con transformaciones culturales. Estos cambios demandan de nosotros, ante todo, la capacidad de fijar nuestra atención en el otro; otro que tiene pensamiento propio y deseos propios e incluso en contravía de los nuestros y desde esta perspectiva sería necesario admitir que no puede haber transformación si la escuela no logra una sólida vinculación con la vida de los sujetos comprometidos en ella, si no reconoce las permanentes transformaciones culturales en valores, estilos de relación, concepciones, sentidos y lenguajes que tienen lugar en la cotidianidad, más allá de sus muros. 
La acción pedagógica demanda hoy, actitudes en el docente para convertirse en orientador y dinamizador de procesos de aprendizaje que atiendan las cosmovisiones de los estudiantes, lo cual haría que el aula se convierta en un lugar de encuentro dialógico y de construcción intersubjetiva, considerando que los niños y los jóvenes son seres activos, con dimensiones plurales y singulares; históricos, sociales y trascendentes, capaces de moldear su propio destino y en consecuencia capaces de decisiones fundadas.

No puede negarse que las condiciones actuales enfrentan al sistema educativo actual a retos que parecerían exigir grandes esfuerzos... Aún así, podría pensarse en el inicio de un proceso enriquecedor del quehacer del docente y de su función social. Con cambios a nivel micro, enraizados en una conciencia y un sentido positivo hacia la transformación emancipadora de las condiciones educativas, es posible vislumbrar un futuro optimista.

Querría enfatizar con FOUCAULT (Citado en: BALL, 1994), sin embargo que en los asuntos que conciernen a la educación "El problema no (es solo) la conciencia cambiante de las personas - o lo que está en sus cabezas- sino el régimen político, económico, institucional de producción de la verdad; (y las) formas de hegemonía social, económica y cultural en las que opera (ese régimen)".

Quiero concluir esta parte, planteando que el país requiere un maestro consciente de la necesidad de ser un mediador cultural y generacional que acepte e impulse las cosmovisiones de niños y jóvenes.

Esta no es en modo alguno una visión pesimista de nuestra situación frente a lo educativo de la evaluación; más que una visión pesimista, creo que constituye un reto al que debemos empezar a responder, casi que inmediatamente, pero con juicio de inventario. En última instancia lo que se propone aquí es una actitud contracultural, una contrapedagogía: independizarse de la cultura que va en contra de la posibilidad de expresión de los individuos y de los colectivos, que aliena la inteligencia, que anula e inculca valores que no pueden calificarse de humanistas. Recordemos una vez más, por si acaso, las agresiones que nos hacemos en la escuela, estudiantes y profesores.

\section{EVALUACIÓN Y ROL DOCENTE}

La evaluación no es un proceso circunscrito al aula de clase o un ritual que se establece independientemente entre el profesor y los estudiantes. La evaluación es un acto que implica de una u otra manera relaciones fundamentales con las concepciones de educación, de pedagogía, de cultura y por ende atiende realidades.

La propuesta que hago implica relacionar conceptos de educación, de pedagogía y de cultura. Una concepción de educación, en tanto acto de humanización; una concepción de pedagogía, en cuanto conocimiento explicito de las prácticas docentes. Ligados a esos dos conceptos, hay que reconocer unas realidades y un país concreto; claro también una cultura, como conjunto de posibilidades, concebida como oportunidad; pensando que cada ser humano crea biografía si los condicionantes psicobiológicos, culturales y sociales se lo permiten, a través o a pesar de la educación (FULLAT, 1996).

Quiero subrayar que imbricado en estas relaciones es importante reiterar que el ser humano contemporáneo busca no solo saber y saber hacer, sino también emocionarse, 
decidir, enjuiciar, optar y esto está en estrecha conexión con las posibilidades que el entorno cultural y social le ofrece.

La educación caracterizada como hecho humano, requiere de una constancia intencional y colectiva. La educación como fenómeno social es un hecho cargado de intencionalidades. Es decir, no hay educación sin compromiso, sin finalidades; la acción educativa es una acción moral, tiene un sentido de intersubjetividad, un modo de "ser con los otros". Pero también hay que decir que la educación no constituye solo actividad, uso, hábito, exterioridad, sino también interioridad, creación, reflexión, compromiso... En la relación social el otro no es jamás objeto experimentable, sino que es parte fundamental de mi relación.

La relación de la educación con el ser humano no se reduce a formarlo como ser social, como ser uno más. Es necesario considerar el evento educativo también en el contexto de la individualidad y esto implica el respeto por el otro, la responsabilidad con el otro, la formación de la singularidad. La acción educativa es también una acción comunicativa, que confronta la vida cotidiana, que es dialógica, que es reconstructiva (CASTAÑO, 1995).

En estas relaciones es evidente la trascendencia que adquiere el rol docente en las instituciones. FOLLARI (1993) plantea que rol docente y práctica institucional son dos problemas claves en el campo de la educación y ubica al docente como gestor decisivo, pero no hacedor exclusivo de los procesos educativos. "nudo de una red de relaciones del sistema educativo, red conflictiva y no siempre armónica, de la cual el docente debe ser consciente si no quiere quedar atrapado y sin decisión propia. El docente como protagonista de la dinámica institucional global, y a la vez, como irrenunciable actor directo en el proceso de promoción del trabajo de aula y sus avatares".

Plantea FOLLARI que profesores y alumnos no suelen ser conscientes de su rol; a menudo por imposibilidad ideológica; en otros casos por pensar el poder como una exterioridad total a la concreción del aula. Sin embargo la sistematización inicial de las prácticas pedagógicas en Bogotá, a través de la Expedición Pedagógica Nacional, muestra que si hay posibilidades; que los docentes pueden contribuir a la transformación de las instituciones si tienen claridad de su rol, comprendiendo el sin sentido... oponiéndose no a la institución en abstracto, sino a sus condiciones concretas y construyendo en su interior formas alternativas.

Es así como en el modelo de educación transmisionista (texto, profesor, tablero, cuaderno, niño), la pedagogía no tenía razón de ser, porque los sentidos y las intencionalidades están dadas a priori; pero lastimosamente no por el maestro...

Hoy es indispensable que el maestro marque los rumbos de la educación colombiana, y ahí es cuando cobra su real dimensión lo pedagógico. Es allí en el conocimiento pedagógico donde el maestro encuentra el sentido del ser docente; pues hoy es el maestro el que reflexiona, el que propone, el que decide, por lo menos así lo plantea la ley.

Los asuntos atinentes a la práctica parecen hacer de ella una entidad compleja (CASTAÑO, 2000). La práctica por el hecho de estar en estrecha conexión con elementos sociales, políticos y culturales está cruzada por múltiples relaciones: cruzada por mecanismos de poder de todo tipo (institucionales, estatales, de conocimiento, de técnicas, ...). Evidentemente no es lo mismo por ejemplo, desarrollar una práctica en una 
institución pública o privada; con los niños o con los adolescentes; en ciencias experimentales o en artes.

La práctica de una u otra manera está influenciada por:

I Las formas de pensar el currículo.

I Las estructuras organizativas institucionales.

/ Las concepciones que tenemos del conocimiento.

I Las normas, los reglamentos, los rituales.

I Los elementos de control como la evaluación.

En la formación docente a la práctica difícilmente se le puede pensar independientemente de la fundamentación teórica, de los propósitos del currículo, de la evaluación, de los contextos culturales locales, de las mentalidades de los jóvenes, de los niños o indiferente a los mecanismos de poder.

Pero la práctica si podría, por su mismo carácter, constituirse en vinculo con las realidades educativas y aportar en múltiples direcciones. La práctica vista como una entidad compleja podría constituirse en eje de formación de los docentes: se trataría de generar un diálogo de sabores entre la escuela y las realidades educativas, en el que se reconozca el aporte y el valor de los otros y reivindicar a la pedagogía como un conocimiento reflexivo que orienta la acción docente; a la pedagogía como la vida misma.... es decir a la pedagogía como un conocimiento que busca la esencia de lo humano y actúa en consecuencia.

Pensar la práctica como un proyecto cultural, social y político impulsaría de otro lado la necesidad de construir conocimiento pedagógico que surja de nuestros propios sentires, de lo que somos como sujetos, como barrio, como ciudad e incluso como nación... acorde con nuestras propias realidades. Las prácticas deberían abrir espacies para pensar en quienes somos y en que queremos ser; pues como dice GARCIA MÁRQUEZ (1983) "la interpretación de nuestra realidad con esquemas ajenos (e impuestos) sólo contribuye a hacernos cada vez más desconocidos, cada vez menos libres, cada vez más solitarios . Esto implica entre otras cosas pensar y mirar la educación en el contexto de nuestros valores históricos, pedagógicos, psicológicos, culturales y sociales.

Habría que empezar a soñar en otras posibilidades, en nuestras propias y genuinas posibilidades, poder vislumbrar el valor de las ideas de los otros, pero para hacer esto posible es fundamental creer en nosotros mismos, valorarnos, sentirnos útiles, pensar que podemos contribuir a los demás... y allí los procesos de evaluación cumplen un papel fundamental; por lo que significan en las relaciones docente-estudiantes.

Seria necesario igualmente admitir que en la práctica se puede construir conocimiento... conocimiento pedagógico y en este sentido un elemento transversal de la práctica como entidad compleja es la investigación educativa. Ella convertiría a la práctica misma en un proceso enriquecedor de la formación docente y de la función social que le compete; pues a un docente en su calidad de investigador, le corresponde internarse en la dinámica de prácticas sociales concretas, como lo son las prácticas educativas, para vivirlas, entenderlas y comprenderlas. La intención es siempre ir más allá de lo evidente, construir una lógica, aportar explicaciones comprensivas que permitan construir conocimiento y orientar, desde la perspectiva del maestro, la acción de realidades educativas concretas; como los procesos de evaluación, por ejemplo. 
Las prácticas también podrían constituirse en el espacio donde se reconoce que el maestro posee un saber práctico que es el que moviliza las acciones escolares, sus propias practicas y formas de organización. Esos sabores aunque no se encuentren dentro de los enfoques discursivos reconocidos, no pueden ser invalidados, descalificados; tenemos la obligación ética de reconocer que son saberes válidos pues surgen de la realidad, están ligados a con-textos de acción histórica y social, surgen de la disposición a obrar con verdad, justicia, sabiduría y prudencia, constituyen experiencias eficaces, que se expresan en la praxis. Un análisis critico será posible, entonces, cuando el saber y la acción organizados puedan tratarse articuladamente y abrirse a la reconstrucción diálogica. (CARR y KEMMIS, 1988).

Lo siguiente que voy a plantear podría parecer una herejía en un mundo moderno que intenta alcanzar a toda costa el mito del progreso. La pedagogía no constituye un discurso racional, vista desde la racionalidad positivista (FULLAT, 1992), tiene que ver con lo irracional, con el humano indefinido, abierto, complejo, infinito, tiene que ver con la conciencia, con el titubeo, con la vacilación y sobre todo con el asombro. La pedagogía tiene que ver con la incertidumbre, con la crisis, con la resolución.

Y la crisis aparece cuando faltan razones convincentes para resolver la incertidumbre: cuando faltan razones lo único que queda es la libertad, la libertad que decide basándose en argumentos y no en pruebas. Por eso la pedagogía no puede ser objeto ni de la actividad científica, ni de la actividad tecnológica; la pedagogía tiene que ver con una indagación metafísica, lo cual no es otra cosa que la decisión.

La otra relación que quiero enfatizar es la relación del ser docente con el conocimiento; relación que a mi modo de ver es fundamental para pensar en el rol docente, en la relación del maestro con la educación y en todos los aspectos que implican concepciones ante el currículo y la evaluación, por ejemplo.

Quiero resaltar algunos aspectos que considero importantes por su carácter orientador. Parto entonces del planteamiento de MÉLICH (1996): nunca puede darse un conocimiento directo de un fenómeno o de un hecho; conocer no es ni reproducir, ni representar; conocer no es representar el mundo sino construirlo.

Esto implica también que no hay un solo modo de conocer y en consecuencia no hay conocimientos más válidos que otros; solo hay conocimientos distintos. Algo es real desde el momento en que se encuentra en relación con nosotros. Como plantea SCHUTZ (citado en : MÉLICH, 1996) "lo que constituye la realidad es el sentido de nuestras experiencias, y no la estructura ontológica de los objetos".

De otro lado recurro a ZULETA (1985) que interpretando a Nietzche en Zaratustra afirma que para conocer, el pensamiento funciona con tres categorías:

- Capacidad de admiración.

- Capacidad de oposición.

- Capacidad de creación.

El espíritu dice Zuleta, es conjunción de estas tres cosas; solo si esas tres cosas se combinan funciona el pensamiento. Cuando cualquiera de las tres se enuncia sola se convierte en frustración, en sombra, en dogmatismo, en una idealización de cualquier tipo o en anarquismo vacío. 
Volviendo entonces a lo pedagógico es necesario reiterar que la dimensión humana es múltiple y polifacética, compleja. Las manifestaciones semióticas de lo humano como dice MÉLICH (1996) tienen que ver con lo religioso, lo artístico, lo político, lo consciente, lo inconsciente, lo técnico, lo filosófico, lo moral, lo científico, lo jurídico, lo social, lo educando... Desde La pedagogía deberíamos admitir que el ser humano significa, analiza y también constata desde la intersubjetividad, pero también desde su subjetividad. Sería necesario tener estas ideas presentes cuando evaluamos.

En lo que respecta a la cultura, se considera que el Homo sapiens (biología más espíritu) le produce sentido a la cultura; pero la cultura (sociedad histórica) produce humanidad y forma al anthropos (FULLAT, 1996). La cultura nos constituye como verdaderamente humanos.

FORQUIN (1993) plantea que nadie puede enseñar verdaderamente si no enseña alguna cosa que sea válida a sus propios ojos”, pero en este planteamiento ¿qué significa la validez de lo que se enseña? $Y$ aquí surge entonces el concepto de cultura y de realidad, de lo que permanece, de lo que se legitima y pienso que la validez de lo que se enseña está determinado por la cultura. Esto quiere decir entonces que la educación conserva! y para nuestro caso, el caso de la realidad colombiana nos encontramos con un desfase histórico que explica mucho de lo que ahora somos y los conflictos que hoy nos aquejan. La cultura de los maestros y de los padres adultos difiere substancialmente de la de las actuales generaciones; nos encontramos ante la crisis frente a "la credibilidad y legitimidad de las representaciones colectivas relativas a los mitos del progreso, la historia y la unidad del sujeto como racionalidad triunfante" (CRUZ, 1994). Crisis frente a las concepciones del tiempo, lo que vale es lo presente, frente al valor de lo sensorial, crisis de ideologías, la historia ha quedado reducida al instante presente por ejemplo... Los nuevos relatos, afirma el mismo autor, tienen que ver con el nihilismo, el goce fugaz de lo inmediato, la utopía de lo sensual, la revalorización de la vida cotidiana y principalmente de lo irracional, de lo intuitivo.

Dice Cruz que en nuestra cultura coexisten"componentes precristianos de naturaleza mítica (restos culturales aborígenes), componentes cristianos de origen hispánico y componentes modernos racionalistas, con origen en la llustración europea, al mismo tiempo con componentes de la cultura del fin de la modernidad". "Vivimos en medio de la magia, la hechicería, la religión, el mesianismo, el atraso y la dependencia tecnológica, la ausencia del espíritu científico... Es decir modernización en el aparato productivo y en los procedimientos, y premodernidad en las cabezas" de los adultos, diría yo, y postmodernidad en el cerebro de las nuevas generaciones. Desfase histórico, reitero, que explica mucho de lo que ahora somos y parte de los conflictos que hoy nos aquejan.

Lo anterior nos evidencia que también en la escuela hay una confrontación tácita entre dos formas de ver el mundo: la de los maestros y la de niños y adolescentes; y parece, como afirma Martín Barbero que esta no es una simple brecha generacional sino que constituye una verdadera y compleja diferencia conceptual en la que ninguno quiere ceder porque, creo yo, es Inconsciente. Habría que hacerla explícita y reconocer que pensamos distinto, que tenemos intereses diversos, que buscamos propósitos diferentes y hasta encontrados.

¿En estas condiciones qué podemos decir de los curricula? sí de la construcción de un currículo se trata, es fundamental explicitar nuestras intencionalidades y compromisos; 
pues no podemos educar sin proponernos algo, cuando se educa, siempre se educa a alguien, para algo.

El currículo es algo más que el vínculo entre la teoría y la práctica educativas. Se constituye en la concreción de un proyecto cultural, de una acción pedagógica que pretende transformar también la práctica docente, entendida como el quehacer docente del equipo educativo y de la institución escolar. Acudiendo a las palabras de STENHOUSE (1981) el currículo es una tentativa para comunicar los principios y rasgos esenciales de un propósito educativo, de forma tal que permanezca abierto a la discusión y a la crítica y pueda ser trasladado efectivamente a la práctica. Toda propuesta curricular es un supuesto a comprobar en la acción.

Y esto supone, de una parte, minar las estructuras de poder propias de los planteles actuales, y de otra, reconceptualizarlas sobre la base de relaciones de poder horizontales y altamente participativas. Esto implica entonces la formación de una comunidad académica de educadores que puedan compartir sus experiencias en la realidad de la escuela y por supuesto que se preocupe por sistematizar sus acciones y fundamentarlas colectivamente.

¿Ante este complejo panorama podemos seguir pensando en la evaluación como control?

\section{LA EVALUACION VISTA DESDE LA LEGITIMIDAD... DEL OTRO}

De los planteamientos que he hecho hasta el momento quiero resaltar aquellos que creo están directamente relacionados con una concepción de evaluación: la cultura pensada como conjunto de posibilidades; la educación como un hecho intencional, lo que ubica al docente como un mediador cultural dada la realidad de una confrontación tácita entre dos formas distintas y válidas de ver el mundo: la de los maestros y la de niños y adolescentes; constituyendo diferencias conceptuales complejas.

Cuando pensamos en la evaluación en consonancia con unas condiciones culturales, no podemos seguir considerándola como resultado final ni como un proceso permanente.

La evaluación en este contexto tendría que ocuparse de:

- Pensar y resolver problemas reales y podría constituirse en proceso de resolución de problemas genuinos y consistentes. Hacer cultura significa fundamentalmente adecuar las ideas a las realidades y ellas se constituyen en torno al sentido de nuestras experiencias, y no sólo alrededor de la estructura ontológica de los objetos, o de los conocimientos disciplinares.

- Interrogarse sobre las actividades y su valor en la construcción del conocimiento. Es decir, pasar de las actividades inventadas para la enseñanza, carentes de sentido, en actividades para ser evaluadas, a pensar en proponer actividades que interesen a los estudiantes y se conviertan en desafíos que los comprometan social y cognitivamente.

- Cambiar el lugar de la evaluación como reproducción por el de la evaluación como producción; producción no solo individual sino también colectiva, incluso de los mismos estudiantes, pero también del equipo docente y en diferentes momentos, en momentos propicios de un proceso suficientemente pensado. 
- Reconocer el papel de los mismos estudiantes en el proceso de evaluación: construir juntos los criterios de evaluación para no generar malentendidos. Es lo que NEWMAN (1991) llama la evaluación dinámica, basado en el concepto de zona de desarrollo proximal de Vigotzky:

En vez de proponer una tarea a los niños y medir hasta qué punto lo hacen mejor e peor, podemos proponérsela y observar cuánta ayuda y de qué tipo necesitan para terminarla satisfactoriamente. De esta manera no se evalúa al niño en forma aislada. Se evalúa al sistema social, para determinar cuanto ha progresado.

Evaluar el sistema social implica de una u otra manera determinar, en términos de logros y obstáculos, el conjunto de posibilidades culturales que la institución provee a niños y jóvenes en formación. En este sentido por ejemplo, MCDONALD (1985) sostiene que la evaluación es un proceso eminentemente político y que los estilos y métodos son expresión de actitudes en relación a la distribución del poder en la educación, el evaluador eligiendo sus prioridades consciente o inconscientemente adopta una postura política.

Susana Colman (1998) afirma que para considerar la evaluación como herramienta de conocimiento, por lo menos se deben cumplir dos condiciones: una condición de intencionalidad. es decir que interese a los sujetos como producto de un trabajo reflexivo y consciente, fundamentado en posturas éticas que se construyen personal y socialmente. Y una condición de posibilidad que no consiste precisamente en seguir un plan previsto, detallado y preciso, sino en ofrecer herramientas para un trabajo que es creado por el propio sujeto y que requiere:

- Que los sujetos puedan desplegar su autonomía, autoestima y autovalía personal.

- Que exista o se genere un medio educativo que admita y valore esas actividades.

- Que se creen las condiciones institucionales y materiales de trabajo docente para su desarrollo.

Estas condiciones quieren decir palabras más o palabras menos que una propuesta de evaluación como proceso de conocimiento, requiere generar confianza; confianza de la institución, de los docentes y de los estudiantes; en últimas confianza en el ser humano y para ello una postura ética es fundamental. Confianza que se da en la medida en que el otro no solo existe, sino que se le reconoce como legitimo; no sea que nos vaya a suceder lo que en el texto de Eduardo Galeano, que precisamente se titula La Celebración de la Desconfianza:

El primer día de clase, el profesor trajo un frasco enorme:

Esto está lleno de perfume — dijo a Miguel Brun y a los demás alumnos- Quiero medir la percepción de cada uno de ustedes. A medida que vayan sintiendo el olor levanten la mano.

Y destapó el frasco. Al ratito no más, ya había dos manos levantadas. Y luego cinco, diez, treinta, todas las manos levantadas.

${ }_{6}$ Me permite abrir la ventana, profesor? Suplicó una alumna, mareada de tanto olor a perfume, y varias voces le hicieron eco. El fuerte aroma, que pesaba en el aire, ya se había hecho insoportable para todos. 
Entonces el profesor mostró el frasco a los alumnos, uno por uno. El frasco estaba lleno de agua.

\section{BIBLIOGRAFÍA}

Ball. S. 1994. Foucault y la Educación. Madrid: Morata.

Camilloni de A.: Celman, S. y otros. 1998. La evaluación de los aprendizajes en e/ debate didáctico contemporáneo. Barcelona: Paidós.

Castaño Cuéllar NC. La educación en e/ contexto social, cultural y político contemporáneo. Ensayo. Octubre de 1995.

Castaño Cuéllar N. C. y Camargo Uribe, L. La práctica educativa en la formacion inicial y sus relaciones con los enfoques epistemológicos y pedagógicos. Ponencia presentada en el II Encuentro de Prácticas Pedagógicas en Colombia. Universidad Pedagógica Nacional. Octubre de 2000.

Combessie, J. 1998. Investigación e innovación: un aporte a la transformación escolar. Santafé de Bogotá: Cooperativa Editorial Magisterio.

Follan, R, 1993. Práctica educativa y rol docente. Buenos Aires: Aique.

Forquin, J. C. 1993. Escola cultura. As bases sociais e epistemológicas do conhecimiento escolar. Porto Alegre: Artes Medicas.

Fullat, O.1992. Filosofías dela educación. Paideia. Barcelona: CEAC.

Galeano, E. 1995. El libro de los abrazos. Bogotá: Tercer Mundo Editores. $5^{\text {a }}$ ed.

García Márquez, 1983. La Soledad de América Latina. Brindis por la Poesía. Corporación Editorial Universitaria de Colombia: Cali.

Hederich, C. y Camargo, A. 1998. Regiones cognitivas en Colombia. Santa Fe de Bogotá: Universidad Pedagógica Nacional.

Litwin, E. "La evaluación: campo de controversias y paradojas o un nuevo lugar para la buena enseñanza". En: Camilloni de A., Celman, s. y otros. 1998. La evaluación de los aprendizajes en el debate didáctico contemporáneo. Barcelona: Paidos.

MAcDONALD, B. "La evaluación y el control de la educación”. En: Gimeno, S. 1985. La enseñanza: su teoría y su práctica. Madrid: Akal Universitaria.

Melich, J.C 1996. Del extraño al cómplice. La educación en la vida cotidiana. Barcelona: Anthropos.

Mockus, A. y otros. 1994. Las fronteras de la escuela. Santafé de Bogotá: Sociedad Colombiana de Pedagogía. 
Newman, D.: Griffin, P y Cole, M. 1991. La zona de construcción del conocimiento. Madrid: Morata.

Roshental, R. y Jacobson, L. 1980. Pigmalión en la Escuela. Madrid: Marova.

Stenhouse, L. 1981. Investigación y desarrollo del curriculum. Madrid: Morata:. $3^{\text {a }}$ ed.

Vygotsky, L. 1995. Pensamiento y lenguaje. Barcelona: Paidós.

Zuleta, E. 1985. La idealización en la vida personal y colectiva. Bogotá: Procultura. 